- Demonstrates the difficulties of matching teeth and the need for an objective and reliable means of shade matching.

- Digital images acquired under standard lighting conditions can provide reliable colour measurements.

- The use of digital images in shade matching will allow technicians to view variations in tooth colour and improve communication between technicians and clinicians.

\title{
The use of digital imaging for colour matching and communication in restorative dentistry
}

\author{
F. D. Jarad, ${ }^{1}$ M. D. Russell ${ }^{2}$ and B. W. Moss ${ }^{3}$
}

\begin{abstract}
Objective To develop a shade matching method based on digital imaging and to compare observers' ability using this method with the conventional one set against a spectrophotometric 'gold standard'. Methods Two Vita Lumin shade guides were used in this study, nine shades being selected from the first Vita Lumin shade guide, $A 2, A 3, A 3.5$, $B 2, B 3, B 4, C 1, C 2$ and $C 3$. A second shade guide was used to match the selected shades. A Nikon Coolpix 990 digital camera with Nikon SB21B ring flash was used to record the digital images of the shade tabs of the two shade guides and the images were processed using Adobe Photoshop software. A total of 27 samples (three replicates of each shade of the nine tabs selected) were matched with a digital shade guide prepared from the digital images of the second shade guide by 10 observers on a computer screen (computerised matching method). The 10 observers also matched the same shade tabs using the conventional matching method simulated in a phantom head. In addition, colour values were obtained from the digital images using Adobe Photoshop and quantified according to an internationally recognised scale as CIELAB colour values, $L^{*}, a^{*}, b^{*}$. The relationship of the digitally derived CIELAB values to the CIELAB values obtained using a reflectance spectrophotometer was investigated.

Results The cross tabulation statistical analysis showed a statistically significant difference $(p<0.001)$ between the conventional method and the computer method with a $43 \%$ and $61.1 \%$ correct match respectively. There was also a statistically significant difference between observers in both methods ( $p<0.001$ and $p<0.04$ for the conventional and computer methods respectively). A statistically significant high correlation of the CIELAB colour values were found between both colour measurement methods $(p<0.001)$.
\end{abstract}

Conclusion The observers' shade matching performance was significantly better with the computer method compared with the conventional one. There was a large variation in the observers' matching ability. The digital camera can be used as a means of colour measurements in the dental clinic.

\footnotetext{
$1^{*}$ Lecturer in Restorative Dentistry, Liverpool University Dental Hospital, Pembroke Place, Liverpool, L3 5PS; ${ }^{2}$ Consultant in Restorative Dentistry/Special Needs, School of Dentistry, Birmingham Dental Hospital (NHS Trust). St Chads Queensway, Birmingham, B4 6NN; ${ }^{3}$ Senior Lecturer, School of Agriculture and Food Science, Queen's University Belfast, Newforge Lane, Belfast, BT9 5PX

${ }^{*}$ Correspondence to: Dr Fadi Jarad

Email:f.jarad@liverpool.ac.uk
}

\section{Refereed paper}

Received 08.12.02; Accepted 14.11.03

doi: $10.1038 /$ sj.bdj.4812559

๑) British Dental Journal 2005; 199: 43-49

\section{INTRODUCTION}

Shade matching is a challenging task in dentistry. The shade guides currently in use lack a systematic arrangement between the tabs, ${ }^{21}$ also there may be different generations (ie different production batches) of tabs within a given guide. ${ }^{15}$ There is also a great variation in colour perception among clinicians. ${ }^{3,5,6}$ Another problem is communication: the technician does not usually see the patient and has to work from a dentist's written prescription based on the shade guide used (eg Vita Lumin A3). This process of communication between the dentist and the technician needs to be improved if better results are to be achieved.

Recent advances in photography and computing have resulted in the widespread use of the digital camera for colour imaging. This new device is capable of recording digital data from an object, which may subsequently be used to produce an image when viewed on a computer, and which may be transmitted via the Internet. Images produced via a digital camera may be analysed using appropriate imaging software enabling the collection of colour values from the whole or parts of such images. This is a much cheaper process than the use of traditional colour measurement devices such as spectrophotometers or colorimeters.

The CIELAB system was developed to produce a uniform colour space. ${ }^{2}$ The Munsell colour order system consists of a number of coloured chips for visual colour matching, arranged in three dimensions of appearance: ${ }^{13}$ value $(\mathrm{V})$, hue $(\mathrm{H})$ and chroma (C). The $\mathrm{L}^{*}$ value in the CIELAB system measures lightness and correlates to value $(V)$ in the Munsell colour order system. The $a^{*}$ and $b^{*}$ values can be used to derive the metric chroma $\left(\mathrm{C}^{*}{ }_{\mathrm{ab}}=\left(\mathrm{a}^{2}+\mathrm{b}^{2}\right)^{0.5}\right)$ and hue angle $\left(\mathrm{h}_{\mathrm{ab}}=\tan ^{-1}(\mathrm{~b} / \mathrm{d})\right)$ as defined by CIE (1986). Figure 1 shows a representation of CIELAB colour space. Metric chroma is represented as the radial distance of the colour coordinates $\left(\mathrm{a}^{*} \mathrm{~b}^{*}\right)$ for the $\mathrm{L}^{*}$ axis. ${ }^{8,16}$ The hue angle $\left(\mathrm{h}^{\circ}{ }_{\mathrm{ab}}\right)$ is represented by the angle of the radial line joining the $\mathrm{L}^{*}$ axis to the colour coordinates $\left(\mathrm{a}^{*}\right.$, $\left.b^{*}\right)$ measured from the $a^{*}$ axis (Fig. 1). A colour difference $(\Delta E)$ between two objects can be calculated according to the following equation:

$\Delta \mathrm{E}=\left(\left(\mathrm{L}_{1}{ }^{*}-\mathrm{L}_{2}{ }^{*}\right)^{2}+\left(\mathrm{a}_{1}{ }^{*}-\mathrm{a}_{2}{ }^{*}\right)^{2}+\left(\mathrm{b}_{1}{ }^{*}-\mathrm{b}_{2}{ }^{*}\right)^{2}\right)^{0.5}$ within the CIE LAB colour system. ${ }^{7,16}$ Under uniformly controlled conditions one unit of $\Delta \mathrm{E}$ was enough for $50 \%$ of observers to detect a visual difference. $^{10,11}$

Spectrophotometric colour measurements are capable of reliably quantifying colour of both extracted teeth and dental porcelain. ${ }^{4} \mathrm{~A}$ few studies have been published on colour meas- 


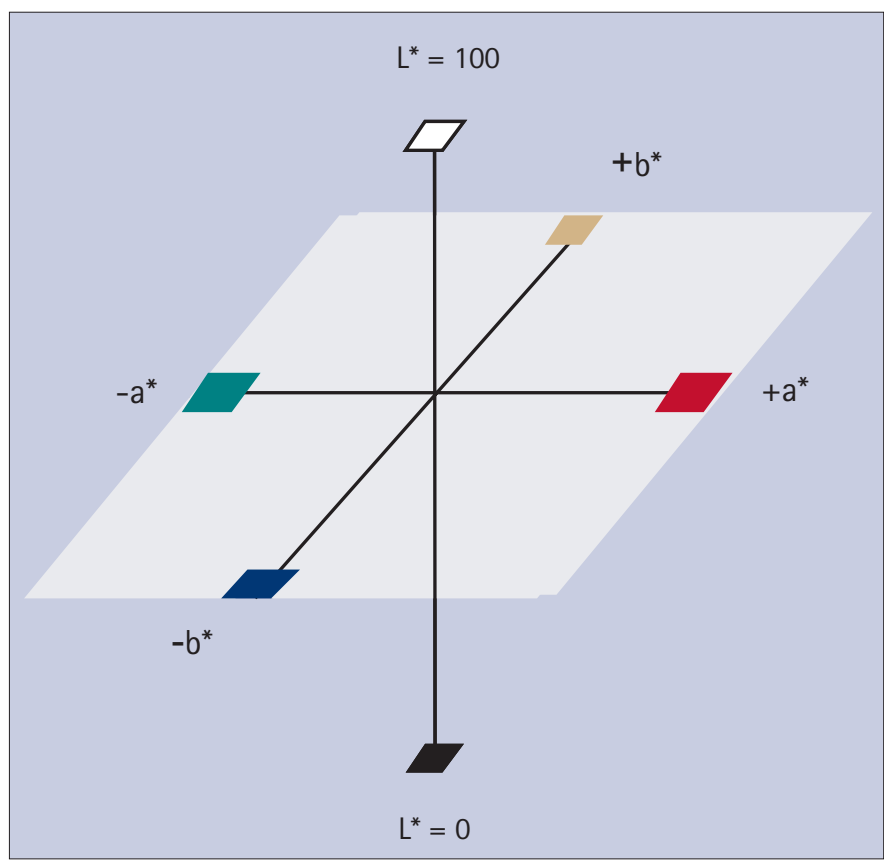

Fig. 1 CIE LAB colour space

urement from digital images obtained by scanning conventional photographs. ${ }^{1,12}$

The aim of this experiment was to use porcelain shade tabs of a Vita Lumin shade guide to compare two methods of shade matching. The first method is the conventional method used by most dentists. The second method was a new computer shade matching procedure. Another aim of this study was to compare the colour values (CIELAB) obtained from the digital images with the colour values (CIELAB) obtained using a reflectance spectrophotometer.

\section{MATERIALS AND METHODS}

\section{Overall experimental design}

The experiment involved 10 observers who were asked to match nine selected shade tabs from one shade guide using a complete set of shade tabs (16) from a second shade guide by either a conventional method or a computer matching method. The 10 observers were selected from the School of Dentistry, The Queen's University Belfast (four postgraduate students from restorative dentistry, two consultants in restorative dentistry and four dental technicians from the conservation laboratory). Two Vita Lumin shade guides (VITA Zahnfabrik, Germany) were used, the nine shades selected from the first Vita Lumin shade guide were: A2, A3, A3.5, B2, B3, B4, C1, C2 and C3. These shades represent the most common shades selected by dentists. ${ }^{20}$ The complete range of shade tabs (16) from the second shade guide were used to match the nine selected shade tabs from the first guide.

The conventional method involved the observers matching shade tabs using shade tabs placed in a phantom head, while the computer matching method involved matching digital images of the shade tabs on a PC screen showing an image of the phantom head. In each matching method each observer was required to match the shade tabs in triplicate. Thus there were 27 (nine shade tabs $\mathrm{x} 3$ replicates of each shade) to be matched by each method (computer and conventional) by the 10 observers giving a total of 540 assessments.

The matching experiment followed a crossover design with the observers split into two groups. The first group undertook two sessions of conventional shade matching and then two sessions of computer matching method. The second group performed the two sessions of the computer matching method first and then the two sessions of the conventional method. The first session in each case involved 13 assessments and the second session 14 assessments. There was no time limit set for each session, at least one day elapsed between each session and each observer completed their set of assessments within two weeks. Details of the two matching procedures, randomisation of samples, and preparation of digital images are given later. Figure 2 shows a flow diagram to summarise the procedures involved.

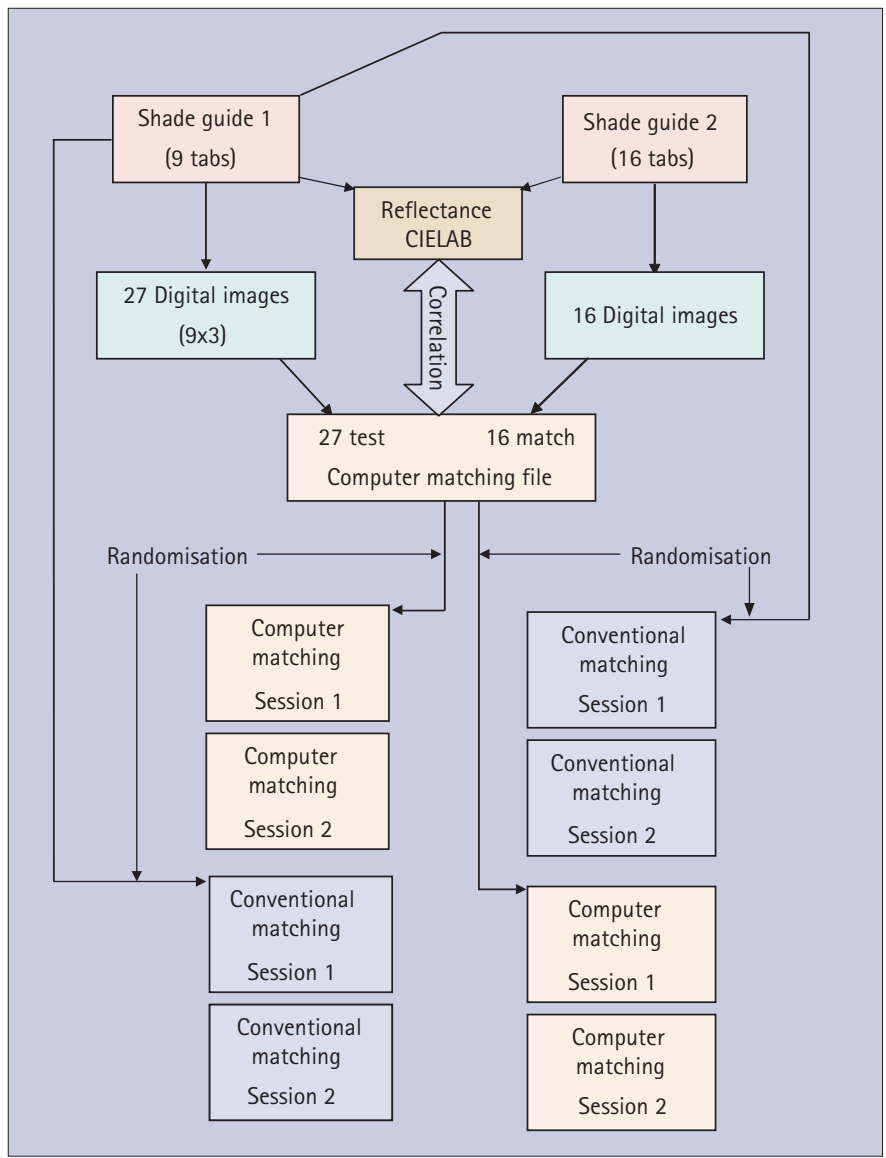

Fig. 2 Flow diagram showing main measurements and sequence of matching sessions

In addition to the matching studies the CIELAB values were obtained from the digital images prepared for the computer matching method and also from the measurements made on the shade tabs using the reflectance spectrophotometer. The relationship between the two sets of values was investigated. Details of equipment are given in the sections Spectrophotometric colour measurements and Digital colour measurements.

\section{Conventional matching method}

A phantom head was attached to a chin rest clamped at a distance of $21 \mathrm{~cm}$ using a U shaped stainless steel bar from a tripod at a height of $1.6 \mathrm{~m}$. Using two steel rods and suitable clamps a colour corrected (colour temperature 6500K, D65) light source (Colour-I-Dent, Waldmann, Paradent, London) used for shade matching in the clinic was clamped vertically so that the centre of the ring light was level with the centre of the mouth of the phantom but at an angle of $45^{\circ}$ to the axis of the bar connecting the chin rest to the tripod. This set up provided consistent illumination and viewing conditions throughout the experiment. All background lighting in the room was also maintained at a consistent level for all sessions.

To undertake the matching, the phantom with a complete set of teeth except for the two central incisors was fixed to the chin rest. The shade tab to be tested was placed in the left central incisor position by the operator and the four digit sample code given to the 
observer. The observer was given a complete Vita Lumin shade guide (the second shade guide) and asked to use their own matching skills (skills usually used in the clinic). No time limit was imposed for the matching. The order of presentation of the teeth for matching was in a random order with each unknown test shade tab given a four digit random number (see section Randomisation of presentation). The matching of the test tabs was undertaken in two sessions; Session 1 involved 13 and Session 2 involved 14 assessments.

\section{Computer matching method}

In the computer matching method the observer was presented with an image of the phantom head with the tooth to be matched (image from first shade guide) positioned in the left incisor position and a space in the right incisor position (all other teeth were in position). The images of the 16 shade tabs of the second shade guide (referred to later as digital shade guide) were arranged in two rows above and below the image of the mouth (Fig. 3). Details of preparation of the digital images and the preparation of the final Adobe Photoshop files are given later (see sections Preparation of the digital shade guide and Preparation of the trial shade tabs).

A practice file was given to each observer and by using the instruction sheet and the operator explanation, they were required to demonstrate their ability to move the shade tabs from their position and match at least one shade until they were confident in the use of the new technique before embarking on the actual trial.

Once the operator was satisfied the observer was able to use the software satisfactorily. The observer was presented with a list of four digit random numbers corresponding to the file containing a particular shade tab. The observer was instructed to open the file in the order presented on the list and undertake the matching by moving the shade tabs from their screen position to the vacant right incisor position for matching. Matching of the shade tabs in the same position within the monitor screen should minimise any effects of variability in the display screen. The identification of the shade tab was recorded when they considered a suitable match had been obtained, along with the file number. The observer then opened the next file on the list and continued matching until all assessments for that session were complete. The matching of the test tabs was undertaken in two sessions; Session 1 involved 13 and Session 2 involved 14 assessments. There was no time limit imposed on the duration of the session and at least one day elapsed between Session 1 and Session 2.

\section{Imaging process}

The Nikon Coolpix 990 digital camera (Coolpix 990, Nikon, Japan) was set on manual mode (M) program, which allowed total control of the shutter speed, and aperture size. The shutter

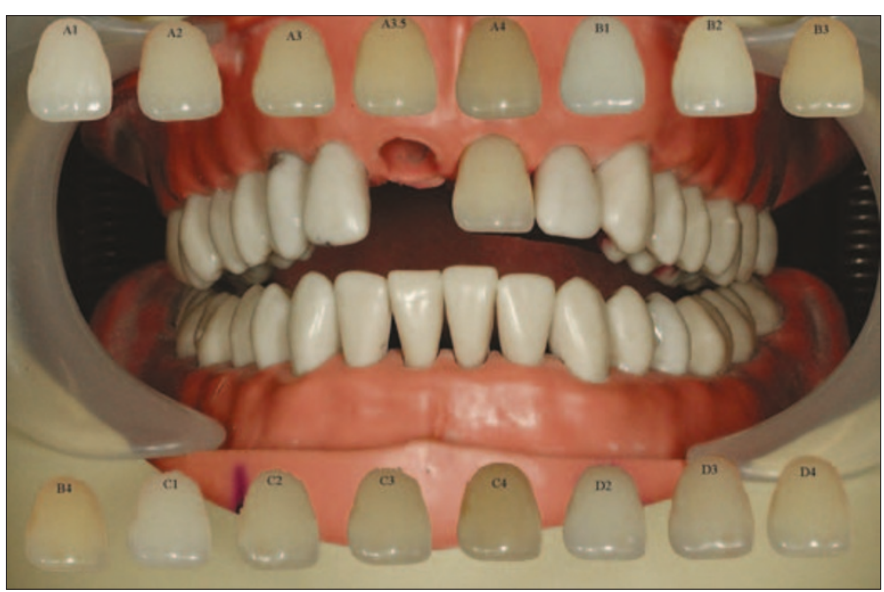

Fig. 3 A digital image with the shade tab to be matched in place and a full set of the digital shade guide (second shade guide) ready for the trial.

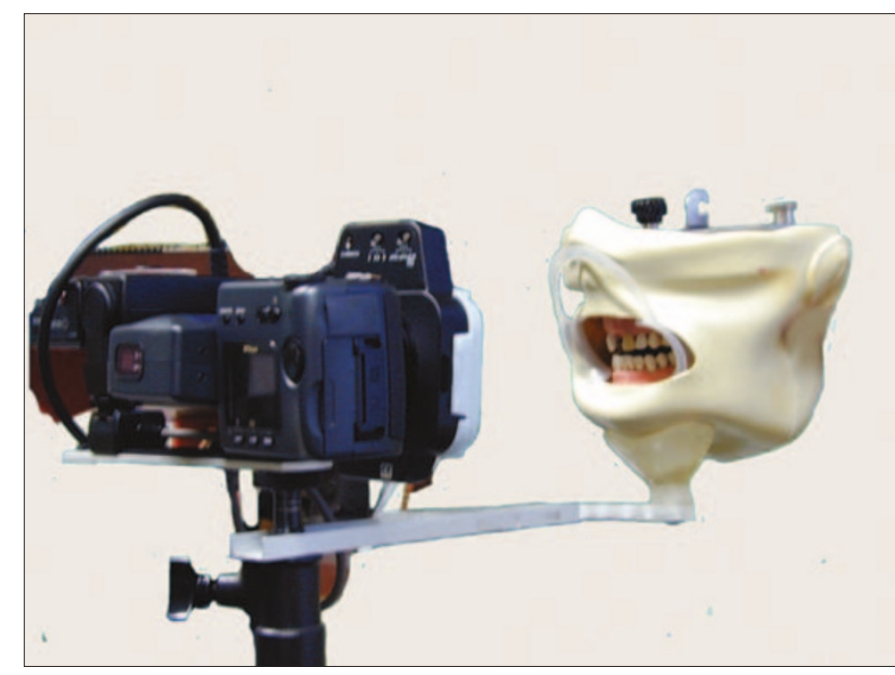

Fig. 4 The Nikon Coolpix 990 digital camera with the chin rest mounted on a tripod.

speed was set at 1/60 sec with an aperture of F9 (the higher the number the smaller the lens opening). The 'white balance' was on 'speed light mode' and the camera was set at 'normal sharpness' and 'standard image adjustment', with 'ISO 100 sensitivity' mode and a lens focal length of $15.5 \mathrm{~mm}$. A ring flash (SB-21b Ring Flash, Nikon, Japan) was attached to the tele-converter lens (TCE2, Nikon, Japan) and then in turn fixed to the camera lens. The flash was connected to the camera using a multi-flash adapter (AS-E900, Nikon, Japan) and the whole set up was fixed to a straight flash bracket. The digital camera was screwed onto a 1.6 $\mathrm{m}$ high tripod and a chin rest fixed on a stainless steel U-shaped bar at a distance of $21 \mathrm{~cm}$ from the tripod top.

The shade tabs of the two shade guides used were detached from their metal holders. The nine shades selected from the first shade guide and the full set of 16 shade tabs of the second shade guide were placed consecutively into the upper left central incisor space in the phantom head. The phantom head was then held against the chin rest on the tripod and a digital image was recorded with the ring flash at the setting described earlier (Fig. 4). Shades selected from the first shade guide were photographed three times with a total of 27 images. To obtain the three replicate photographs for each shade tab, the shade tab was removed from the phantom head, replaced and then re-photographed using the same camera settings. Each shade tab of the second shade guide was photographed only once with a total of 16 images. The digital images taken were then imported into Adobe Photoshop (version 5.5) for preparation of the digital shade guide and digital colour measurement.

\section{Preparation of the digital shade guide}

The total of 16 images from the second shade guide were used to prepare the digital shade guide. Each image was opened using Adobe Photoshop Software, version 5.5 (Adobe system incorporated, USA). The shade tab in the images was first selected and the selection was layered so that the images of the shade guide could be transferred to an Adobe image file (PSD format file) with a transparent background. This file format allows for multi layer image, which enables the operator to move each shade tab individually across the image area and also to control the visibility of each layer. The images of the shade tabs were then aligned at the top and bottom border of the image and they were labelled (ie A1, A2, etc) as shown in Figure 5.

\section{Preparation of the trial shade tabs}

The 27 images of the selected nine shades were transferred to the digital shade guide file as a background layer using Adobe 


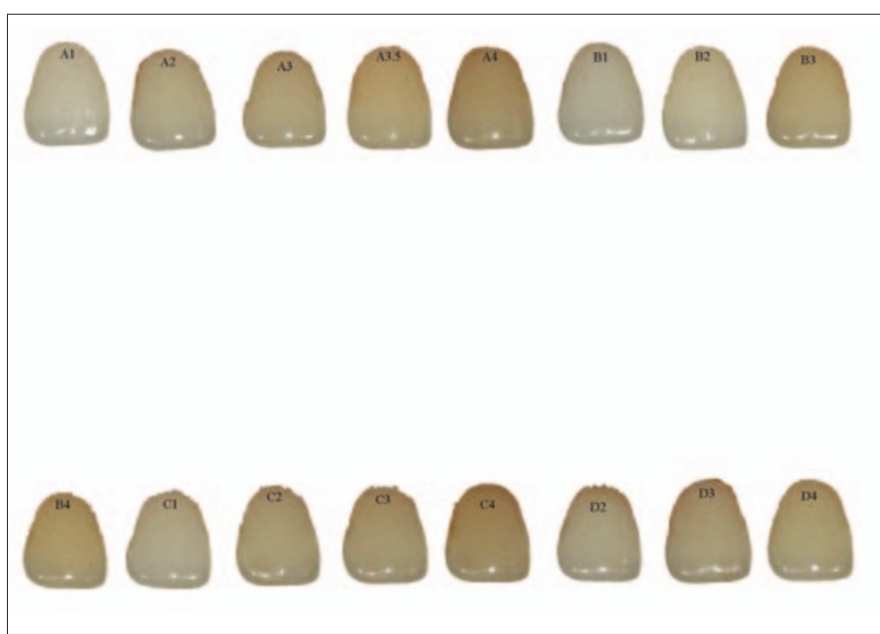

Fig. 5 A digital image file with the images of the second shade guide shade tabs individually layered (the digital shade guide).

Photoshop software (version 5.5). The resulting saved files had the shade tab to be matched from the first shade guide and the complete set of shade tabs from the second shade guide (Fig. 3). A total of 27 trial image files were prepared for the study.

\section{Randomisation of samples}

To reduce bias from order of presentation the shade tabs to be matched (27 assessments, nine tabs $\mathrm{x} 3$ replicates) were presented in a different random order for each matching method and observer. Twenty random lists were produced for the nine selected shades. Within each random list each shade to be matched was duplicated three times with a total of 27 observations for each list (i.e. nine shade tabs $\mathrm{x} 3$ replicates). Each list was split so that the first 13 random observations were allocated to Session 1 and the remaining 14 observations were allocated to Session 2. Each observation (colour match) was coded with a four digit random number so that no sample could be identified or any bias inferred during the matching procedure.

\section{Colour measurement}

\section{Digital colour measurement}

Colour measurement of the digital images of three replicate images of the nine selected shades from the first shade guide and the 16 shade tabs of the second shade guide were undertaken. Adobe Photoshop software (Version 5.5) was used to view and measure the colour of the shade tabs digital images. Image files were opened in Adobe Photoshop software. An area of $4 \mathrm{~mm}$ diameter was selected from the middle third of the digital image of the shade tab using the 'circle marque' tool within the Adobe Photoshop software. This area (4 mm diameter) was selected from the middle third of the shade tab tooth surface as it was found that this position could be reproducibly obtained on all the shade tab images. All digital colour measurements were made with the tooth in a central position within the monitor. The 'histogram' window within the software was selected to obtain average colour values of R,G,B of the selected area (4 mm diameter). These R, G B values were converted to CIELAB colour coordinates using Colour Metric Converter software (Color Eng Inc, USA). The reason for using this conversion software was that in the Adobe Photoshop version used (version 5.5) it was found that $\mathrm{L}^{*}$ values were given on a scale of 0 to 256 rather than 0 to 100 . This problem is also evident as some authors ${ }^{1}$ have published $L^{*}$ values obtained directly from Adobe Photoshop using a 0 to 256 scale. The converted data was then entered into a spreadsheet (Microsoft Excel) and colour differences between the corresponding shade tabs of the two shade guides were calculated according to CIE (1986). ${ }^{2}$

\section{Spectrophotometer colour measurements}

The colour of the shade tabs of the two Vita Lumin shade guides were measured using a reflectance spectrophotometer (Monolight, Macam Photometrics, Livingstone, Scotland). The reflectance spectrophotometer consisted of a Model 6800 controller, with a 6100 monochromator, blaze $300 \mathrm{~nm}, 0.45 \mathrm{~mm}$ slit width, high gain photomultiplier detector controlled by Monolight software. The $45^{\circ} / 0^{\circ}$ reflectance head was attached to the tungsten halogen light source and photomultiplier using fibre optics. The lens assembly within the $45^{\circ} / 0^{\circ}$ reflectance head was adjusted to give an illumination elliptical area of 8 by $6 \mathrm{~mm}$ and the reflectance was collected from a $4.5 \mathrm{~mm}$ diameter circle.

The spectrophotometer was calibrated before each colour measurement session as follows: a black plate was used in the light beam path to calibrate for zero reflectance; a built-in HeliumNeon laser source was used for wavelength calibration (peak between $632.75 \mathrm{~nm}-633.00 \mathrm{~nm})$. All measurements were made relative to a standard white tile (British Ceramic Research Association). This reference spectrum was taken to be $100 \%$ reflectance for future measurements. The reflectance spectrum for the measured samples was used to calculate the CIE XYZ tristimulus coordinates using built-in software. A 100\% reflectance calibration was undertaken before each shade tab measurement to reduce possible instrumental drift.

The shade tab was removed from its metal holder and placed in plastic mould (Vita mould) designed from grey plastic material to hold the frontal flat surface of the shade tab flush with the surface of the mould. The Vita mould was positioned on the measurement table so that the illumination beam $\left(45^{\circ}\right)$ was positioned in the middle third of the shade tab surface tab (as described in digital image measurement). Guides made from black plastic strips were fixed to the measurement table as reference for precise positioning of the mould for repeat measurements. The measurement table was raised so that the flat surface of the mould and aligned shade tab was flush with the lower surface of the $45^{\circ} / 0^{\circ}$ head (Fig. 6). The reflectance spectrum of the shade tabs was obtained at $1 \mathrm{~nm}$ intervals and the CIEXYZ values were calculated for D65 illumination and $2^{\circ}$ observer curve using the built in software. To obtain replicate measurements of the shade tabs, the shade tab was removed from its mould, replaced and following the measurement of the standard white reference tile the shade tab was positioned using

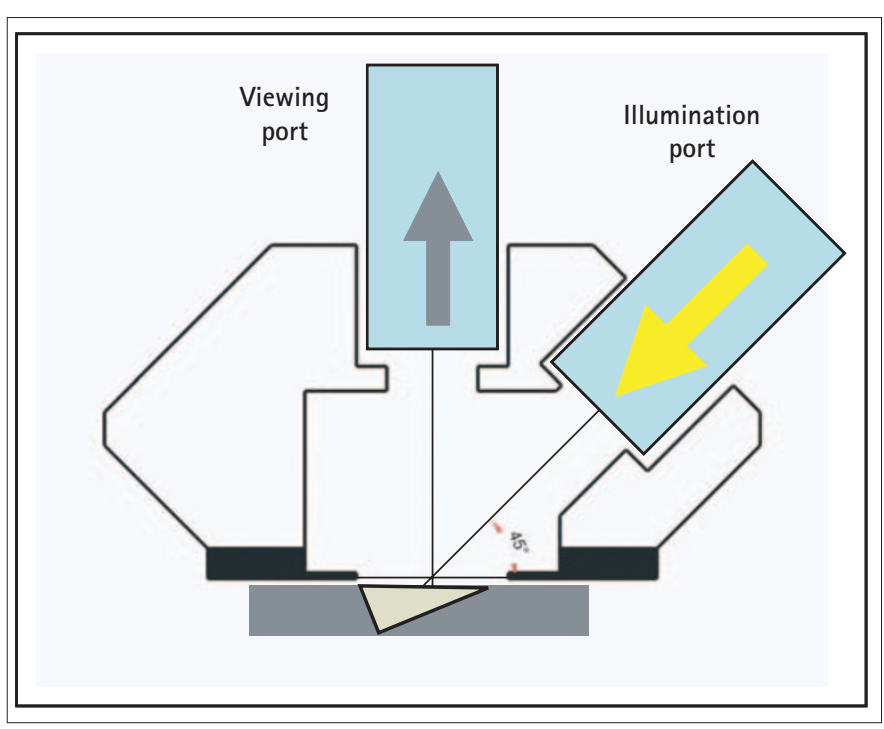

Fig. 6 The illumination/ viewing geometry for the spectrophotometer measurement head in relation to the shade tab sample. 
the guides and a reflectance spectrum obtained. This was repeated so the three replicate spectra were obtained for each shade tab.

The CIE XYZ data was then imported into a spreadsheet (Microsoft Excel) and the X, Y and Z colour tristimulus values converted to CIELAB colour coordinates using the following equations: ${ }^{7}$

$$
\begin{aligned}
& \mathrm{L}^{*}=\left(116^{*}(\mathrm{Y} / \mathrm{Yn})^{(1 / 3)}\right)-16 \\
& \mathrm{a}^{*}=500 *\left((\mathrm{X} / \mathrm{Xn})^{(1 / 3)}-(\mathrm{Y} / \mathrm{Yn})^{(1 / 3)}\right) \\
& \mathrm{b}^{*}=200^{*}\left((\mathrm{Y} / \mathrm{Yn})^{(1 / 3)}-(\mathrm{Z} / \mathrm{Zn})^{(1 / 3)}\right)
\end{aligned}
$$

$\mathrm{Xn}, \mathrm{Yn}$, and $\mathrm{Zn}$ are X Y Z values of a reference white for D65 illumination and $2^{\circ}$ observer. $^{7}$

\section{Statistical analysis}

A chi-squared contingency analysis was used to test the difference between the two matching methods and observers. A Spearman correlation was used to correlate the CIELAB colour values of the shade tabs obtained using the reflectance spectrophotometer with the CIELAB values obtained using the digital image. The software used was the NCSS 2000 statistical package.

\section{RESULTS}

Table 1 shows the number of correct and incorrect observations for both the conventional shade matching method and the computer shade matching. Observers overall had a 52\% (281) correct match for both methods from a total of 540 observations. The conventional matching method had a $43 \%$ correct match, whilst there were $61.1 \%$ correct for computer matching. The cross tabulation statistical analysis (Chi-squared contingency analysis) showed a statistically significant difference $(\mathrm{p}<0.001)$ between the conventional method and the computer method.

Table 1 The number of correct and incorrect observations for both the conventional matching method and the computer matching.

\begin{tabular}{llll}
\hline Shade Matching & $\begin{array}{l}\text { Conventional } \\
\text { Matching }\end{array}$ & $\begin{array}{l}\text { Computer } \\
\text { Matching }\end{array}$ & $\begin{array}{l}\text { Mean \% and Grand } \\
\text { Total }\end{array}$ \\
Incorrect & $57.0 \%(154)$ & $38.9 \%(105)$ & $48.0 \%(259)$ \\
Correct & $43.0 \%(116)$ & $61.1 \%(165)$ & $52.0 \%(281)$ \\
Grand Total & $100 \%(270)$ & $100 \%(270)$ & $100 \%(540)$ \\
\hline Chi-square $=17.815, p<0.001$ & &
\end{tabular}

\begin{tabular}{|c|c|c|c|c|}
\hline \multirow{3}{*}{ Observer } & \multicolumn{2}{|c|}{$\begin{array}{l}\text { Conventional Matching } \\
\text { Method }\end{array}$} & \multicolumn{2}{|c|}{$\begin{array}{l}\text { Computer Matching } \\
\text { Method }\end{array}$} \\
\hline & Correct & Incorrect & Correct & Incorrect \\
\hline & $\%$ (number) & number & $\%$ (number) & number \\
\hline 1 & $44.4(12)$ & (15) & $48.1(13)$ & (14) \\
\hline 2 & $25.9(7)$ & $(20)$ & $77.8(21)$ & (6) \\
\hline 3 & $85.2(23)$ & (4) & $66.7(18)$ & (9) \\
\hline 4 & $48.1(13)$ & (14) & $40.7(11)$ & (16) \\
\hline 5 & $18.5(5)$ & $(22)$ & $66.7(18)$ & (9) \\
\hline 6 & $33.3(9)$ & (18) & $70.4(19)$ & (8) \\
\hline 7 & $22.2(6)$ & (21) & $48.1(13)$ & (14) \\
\hline 8 & $29.6(8)$ & (19) & $77.8(21)$ & (6) \\
\hline 9 & $74.1(20)$ & (7) & $63.0(17)$ & (10) \\
\hline 10 & $48.1(13)$ & (14) & $51.9(14)$ & (13) \\
\hline $\begin{array}{l}\text { Mean } \% \text { and } \\
\text { Grand Total }\end{array}$ & $43.0 \%(116)$ & (154) & $61.1 \%(165)$ & $(105)$ \\
\hline & \multicolumn{2}{|c|}{ Chi-square $=48.426 p<0.001$} & \multicolumn{2}{|c|}{ Chi-square $=17.532 p<0.05$} \\
\hline
\end{tabular}

Table 2 Observer ability to match shades for each individual method (the conventional and computer methods).
The ability of individual observers to match correctly within each method is shown in Table 2. The Chi-squared analysis shows that in both the conventional matching and the computer matching method there were a significant difference $(p<0.001)$ between observers (Table 2). The best observer (Observer 3) using the conventional method was able to match correctly $85 \%$ of the shade tabs (23) while Observer 7 was only able to match $22.2 \%$ of shade tabs presented. Although the observers using computer matching were statistically different, the $\mathrm{p}$ value was 0.04 (compared to $p<0.001$ for the conventional method) and the variation between observers was smaller in comparison with conventional method. Observers 2 and 8 had the highest correct score in the computer matching method $(77.8 \%)$, while the lowest correct score was 48.1\% for Observers 1 and 7.

The ability of the observers to match porcelain shade tabs in two matching sessions is shown in Figures 7 and 8. Using the conventional matching method, the ability of the observers to match colour increased in general from Session 1 to Session 2. Observers 5 and 8 were the only observers to show a decrease in their ability to match (Fig. 7). Using the computer matching method, there was in general a very small increase in the observers' ability to match in Session 2 compared to Session 1. The ability of matching decreased in Observers 2, 7 and 9 from Session 1 to 2. Observer 2 was notable in that his ability decreased from approximately $90 \%$ to $60 \%$ (Fig. 8).

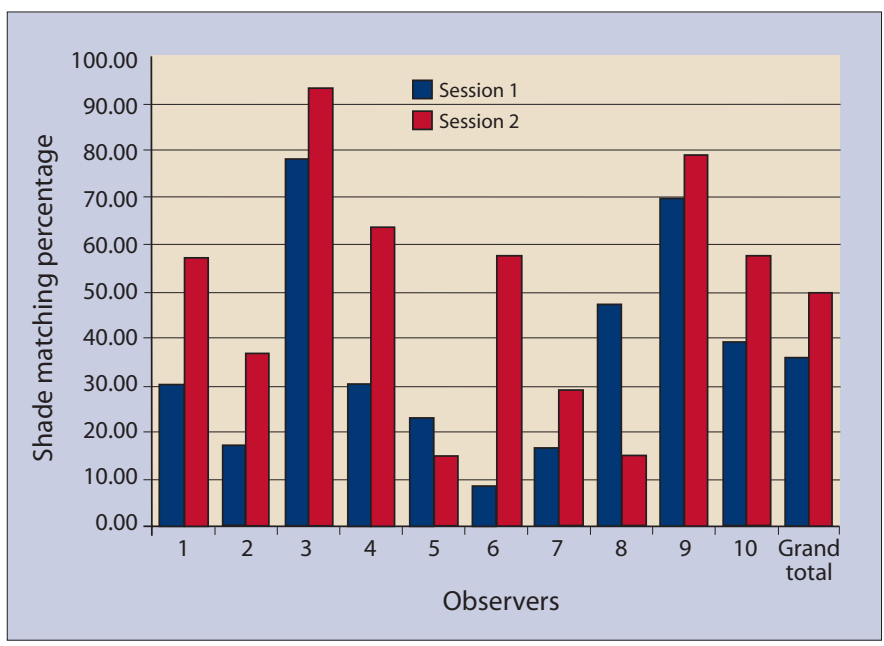

Fig. 7 The matching ability of the observers in the two matching sessions for the conventional matching method

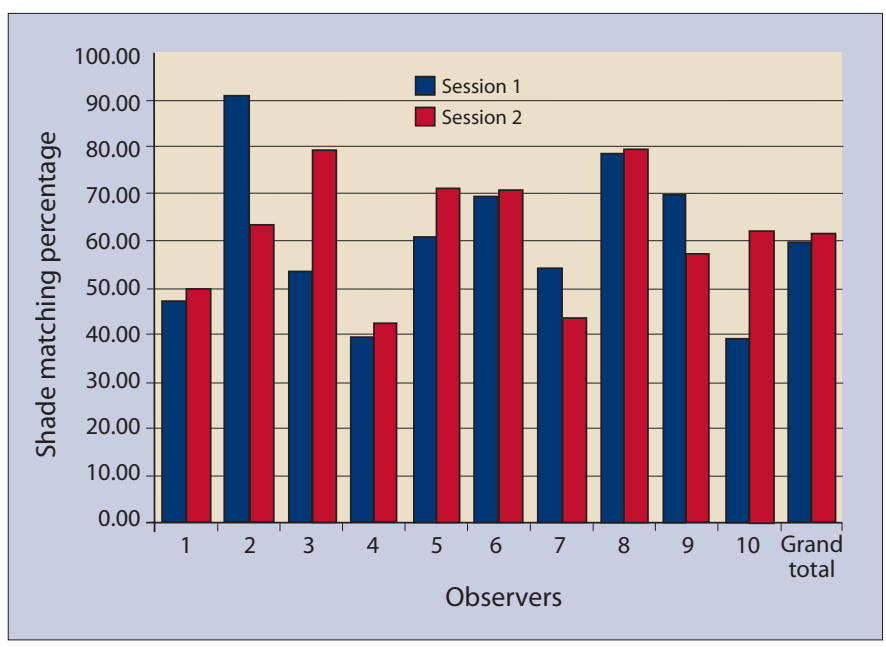

Fig. 8 The matching ability of the observers in the two matching sessions for the computer matching method 
The plot of $\mathrm{L}^{*}, \mathrm{a}^{*}$, and $\mathrm{b}^{*}$ colour values of the three replicates of the nine Vita Lumin shade tabs (A2, A3, A3.5, B2, B3, B4, C1, C2 and $\mathrm{C} 3$ ) for shade guide 1 and the full range (16 shade tabs) of the Vita shade guide 2 obtained by the spectrophotometer and the digital camera is shown in Figures 9, 10 and 11. The correlation between the $L^{*}, a^{*}$ and $b^{*}$ values of the spectrophotometer and the digital camera was statistically significant $(p<0.001)$ for both shade guides. The coefficient of variation for the triplicate measurements for $\mathrm{L}^{*}$ ranged from 0.05 to 0.49 for spectroscopic method and from 0.08 to $1.39 \%$ for the digital images.

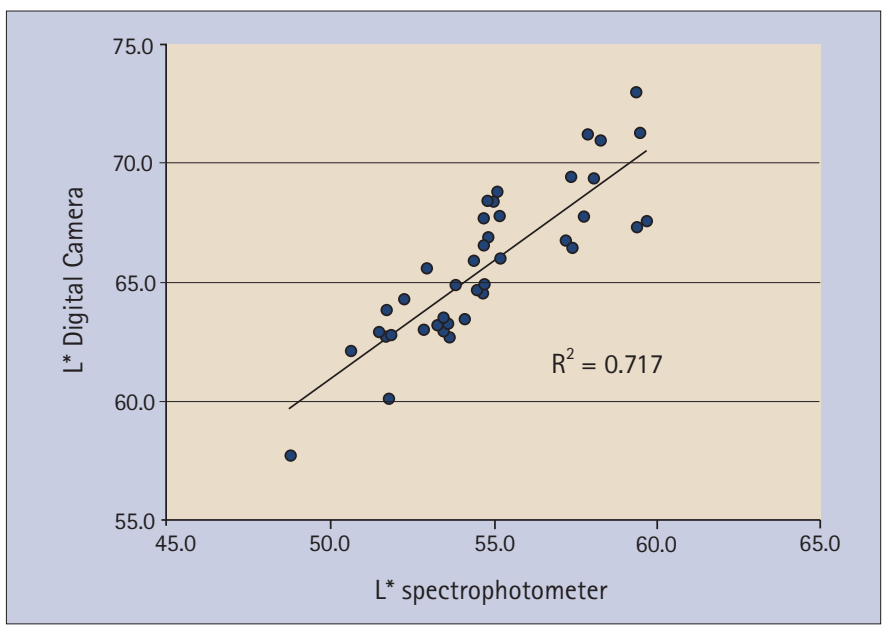

Fig. 9 Scatter plot of $\mathrm{CIE} \mathrm{L}^{*}$ colour values of the shade guide 1 and 2 using spectrophotometer and digital imaging $(R=0.846, p<0.001)$.

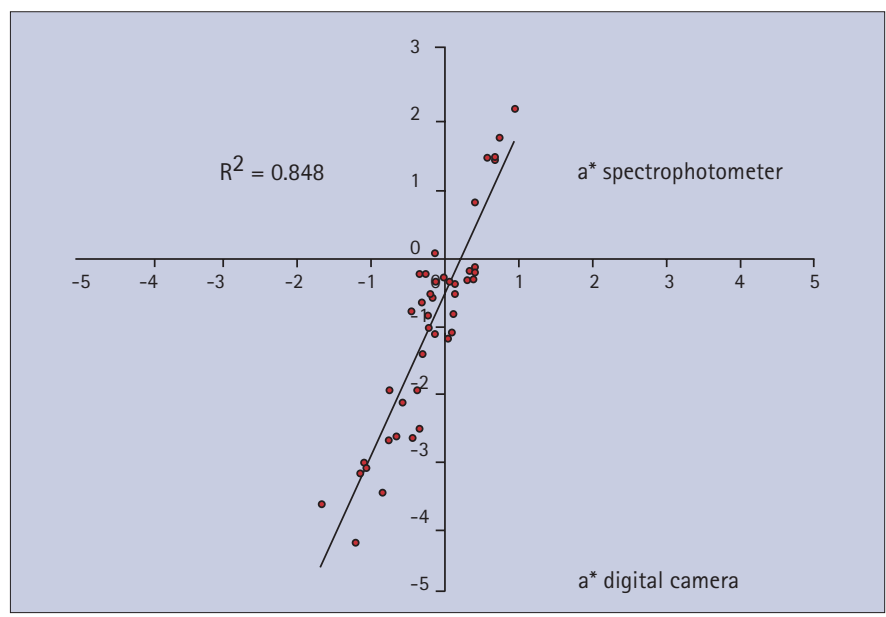

Fig. 10 Scatter plot of CIE a* colour values of the shade guide 1 and 2 using spectrophotometer and digital imaging $(R=0.920, p<0.001)$.

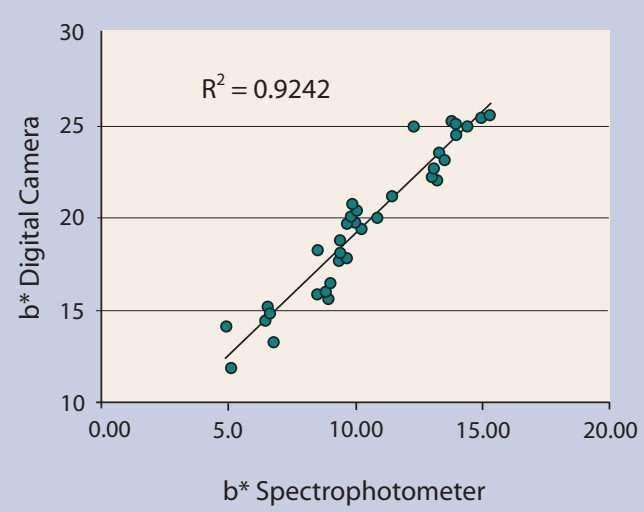

Fig. 11 Scatter plot of CIE $b^{*}$ colour values of the shade guide 1 and 2 using spectrophotometer and digital imaging $(R=0.961, p<0.001)$.

\section{DISCUSSION}

In this study it was found that the computer matching method was statistically different from the conventional matching method with $61 \%$ correctly matched shade tabs compared with $43 \%$ for the conventional method. The observers in general made comments that they found the computer matching method easier than the conventional method and seven out of 10 preferred the computer method despite the fact that they had had relatively longer experience using the conventional method. The computer matching method allowed both the shade guide and tooth to be viewed on the same screen and the shades to be moved around, placed adjacent to, or even overlapping the tooth to be matched.

In this study the observers matched only $43 \%$ of the shades correctly, which is a slightly lower figure than in previous studies. ${ }^{5,6}$ In Geary and Kinirons' study 64\% correct matches were scored by the 70 observers, by using two Vita shade guides similar to the present study, but shade matching was carried out on the laboratory bench and the shade selected for matching had a wide range of colour (A1, A2, B1, B2, C1, C2, D2 and D4). ${ }^{5}$ On the other hand Horn et al had 50\% correct in day -1 and 65\% correct in day 14 using only six shades of the Vita shade guide to match 20 extracted natural teeth. ${ }^{6}$ The limited number of shade tabs used in that study makes it relatively easier to select a shade and increases the probability of getting the 'right' shade. Another study, which may explain the matching differences between studies reported in the literature, showed that it is more difficult to match shades intraorally than in the laboratory, with 43\% and 55\% 'correct matches' respectively. ${ }^{18}$ In the current study it was found that although there was improvement in performance between Session 1 and Session 2, the improvement was greater in the conventional method than the computer method. This improvement could be due to experience gained from the first session. These results indicate the need for training and experience in colour matching. The computer matching method provides an ideal tool to be adapted for such training purposes.

The ability of the observer to match colour was found in this study to be variable. The observers' overall matching ability for both methods ranged from as low as 35\% to as high as 75\%. This is consistent with findings that there is a great variation in colour perception among clinicians. ${ }^{3,5}$ In the present study, although statistically significant difference between observers was found in both methods, the computer matching method showed a smaller variation when compared with the conventional method, indicating a more reliable performance.

The two sets of the Vita Lumin shade guide used in this study were assumed to be identical as claimed by the manufacturer. However, shades guides may have different generations of tabs within a given guide, which means that there is variation between different production runs of shade guides. ${ }^{14,15,17}$ In the present study the difference between respective shade tabs of the two shade guides $\Delta \mathrm{E}$ ranged between 0.3 and 2.3 units. These $\Delta \mathrm{E}$ values are still considered to be acceptable colour differences ${ }^{10}$. 0 'Brien et al. found colour variation for three different batches of body opaque samples ranged from 0.55 to $3.38 \Delta \mathrm{E}$, depending on shade and brand. ${ }^{14}$ Rinke et al. (1996) found colour differences of 2.4 to 9.5 $\Delta \mathrm{E}$ between three batches of materials. ${ }^{17}$ The differences in $\Delta \mathrm{E}$ were attributed to $\mathrm{L}^{*}$ and $\mathrm{b}^{*}$ with very little change in $\mathrm{a}^{*}$ values. These reports highlight the problems in standardisation of shade guides used for colour matching of teeth.

In this study high correlations were found between the spectrophotometer and the digital camera in all the CIE L*, $\mathrm{a}^{*}$, and $\mathrm{b}^{*}$ colour coordinates when the Vita Lumin shade tabs were measured. Although for $\mathrm{L}^{*}$ the slope of the line was close to one, the intercept was not zero but 11.3 . Similarly for $\mathrm{a}^{*}$ and $\mathrm{b}^{*}$ the respective slopes and intercepts were 2.41 and 0.53 for $\mathrm{a}^{*}$ and 1.32 and 
5.94 for $b^{*}$. The CIELAB values for translucent materials, such as teeth, depend critically on the area of illumination and viewing. ${ }^{9}$ Thus the spectrophotometer CIELAB values are not absolute but are geometry dependent. ${ }^{9}$ It must also be remembered that the digital images were obtained using a ring flash, which has a spectral energy curve that is not the same as D65. In the future, by including colour standards in the same image, adjustment for these aspects of digital colour imaging could be made using various algorithms to calibrate the values. The reproducibility of the digital images as measured by the coefficient of variation of $L^{*}$ values varied between $0.08 \%$ to $1.39 \%$ compared to the coefficient of variation 0.05 to $0.49 \%$ of the mean for the same shade tabs measured using the reflectance spectrophotometer. The ring flash did introduce some highlights and careful lighting would be needed to control this. The $\mathrm{L}^{*}$ values from areas including highlights would be expected to be higher than those from selected areas where the highlights were not included. ${ }^{9}$

This is the first attempt to quantify the CIELAB colour values of shade tabs using the digital camera and compare them to the spectrophotometer. However, further work is required to establish how factors such as lighting and reproducibility of digital images influence the measurements. The high correlation found between the two methods opens the way for a large number of clinical studies in bleaching and shade evaluation. These studies were not previously possible because of the limitation of the spectrophotometer in terms of requiring a relative large measurement area, geometry problems caused by tooth curvature and the high cost.

In this study the computer matching method using the digital camera was developed to produce a new method of colour matching to improve the observer's (dentist's) ability to match the tooth colour. In situations where the clinician may not be able to find a single shade tab to match the tooth, a prescription may be made combining shades from a number of tabs. These tabs may relate to different areas of the tooth; the use of digital images allows the technician to evaluate the different shade tabs in relation to different areas of the tooth. The technician is then able to use their technical expertise of the ceramics to build up a prosthetic tooth that matches the patient's tooth much better than previously when it was just based on notes from the clinician. The dental technician can also benefit by improved communication via a computer link instead of receiving the tooth colour as a shade number: the digital images can be sent via the internet to the laboratory and the technician can also match the tooth colour on the computer screen (computer matching method) and by the colour difference values which the computer can calculate automatically. The digital image gives more information about tooth colour across the surface, shape and special characteristic features the technician may need to produce an acceptable restoration.

\section{CONCLUSION}

- A new computer matching method was established and found to be superior to the conventional matching method within the parameters of the study.

- There is a large variation in observers' matching ability.

- A very high and statistically significant correlation was found to exist between the spectrophotometer and digital camera for all CIE L*, $\mathrm{a}^{*}$, and $\mathrm{b}^{*}$ colour coordinates.

- The digital camera can be used for colour measurements in the dental clinic.

- Computer matching may improve dentist-laboratory communication.

The authors would like to thank all the participants in this study. We would also like to thank Dr Richard Gray for his help in preparing the figures for this paper.

1. Bentley $\mathrm{C}$, Leonard R H, Nelson C F, Bentley S A. Quantification of vital bleaching by computer analysis of photographic images. J American Dent Assoc 1999; 130: 809 816.

2. CIE publication No. 15.2. CIE Colorimetry. 2nd Ed. Paris: Central Bureau of the $\mathrm{CIE}_{\mathrm{a}}$ 1986.

3. Culpepper W D. A comparative study of shade-matching procedures. J Pros Dent 1970; 24: 166-173.

4. Douglas R D, Przybylska M. Predicting porcelain thickness required for dental shade matching. J Pros Dent 1999; 82: 143-149.

5. Geary J L, Kinirons M J. Use of common shade guide to test the perception of differences in the shades and value by members of the dental team. Rest Dent and Prim Dent Care 1999; 6: 107-110.

6. Horn D J, Bulan-Brady J, Hicks M L. Sphere spectrophotometer versus human evaluation of tooth shade. J Endo 1998; 24: 786-790.

Hunt R W G Measuring colour. $2^{\text {nd }}$ Ed. Chichester: Ellis Horwood Limited, 1991.

8. Hunter R S. The measurement of appearance. New York: John Wiley and Sons, 1975

9. Jarad F J. Application of spectrophotometry and computerised digital imaging to colour perception in restorative dentistry. PhD Thesis. Queen's University Belfast, 2001

10. Johnston W M, Kao E C. Assessment of appearance matched by visual observation and clinical colorimetry. J Dent Res 1989; 68: 819-822

11. Kuehni R G, Marcus R T. An experiment in visual scaling of small color differences. Color Res and App 1979; 4: 83-91.

12. Mccaslin A J, Haywood V B, Potter B J, Dickinson G L, Russell C M. Assessing dentine color changes from nightguard vital bleaching. J Amer Den Assoc 1999; 130: 14851490

13. Newhall S M, Nickeson D, Judd D B. Final report on the O.S.A. Sub committee on spacing of Munsell colours. J Opt Soc America 1943; 33:385-418.

14. O'Brien W J, Kay K S, Boenke K M, Groh C L. Sources of colour variation on firing porcelain. Dent Mat 1991; 7: 170-173.

15. Preston J D. Current status of shade selection and color matching. Quint Int 1985; 16: 47-58.

16. Riggs B. Colorimetry and the CIE system in colour physics for industry. 2nd Ed. Edinburgh: R. McDonald Pub. Society of Dyers and Colorists, 1997

17. Rinke $S$, Hüls $A$, Kettler M J. Colorimetric analysis as a means of quality control for dental ceramic materials. Euro J Pros RestDent 1996: 60:297-303.

18. Schwartz R S, Duke E S, Haney S E, Herbold E T. Evaluation of a custom porcelainfused-to-metal shade guide. Quint Int 1986; 17: 181-184

19. Seghi $R \quad R$, Johnston $W M, 0$ Brien $W$ I. Spectrophotometric analysis of color differences between porcelain systems. J Pros Dent 1986:56:35-40.

20. Smith $P$ W, Wilson $N$ H. Shade selection for single-unit anterior metal ceramic crowns: a 5-year retrospective study of 2,500 cases. Int J Pros 1998; 11: 302-306.

21. Sproull R C. Color matching in dentistry. Part II: Practical applications of organisation of color. J Pros Dent 1973: 29: 556-566. 